\title{
Attitude as a Predictor of Trust in Food Safety: A Study of Malaysian Chinese College Students
}

\author{
Shujen Lee Chang, Cze Chiun Wong* \\ Department of Psychology, Asia University, Taiwan
}

Copyright (C) 2015 by authors, all rights reserved. Authors agree that this article remains permanently open access under the terms of the Creative Commons Attribution License 4.0 International License

\begin{abstract}
Objective: This study explored the relationship between consumers' trust in and attitude towards food safety and, then, examined the prediction of trust in food safety by the attitude towards food safety. Method: One hundred and eight Malaysian Chinese college students (42 men, 66 women) completed online survey. Trust in food safety included dimensions of ways of shopping, food quality, cooking methods, consumption situation, and purchasing motives. Attitude towards food safety consisted of positive and negative aspects. Results: Positive attitude towards food safety significantly correlated to and successfully predicted trust in food safety concerning cooking methods and consumption situation. On the other hand, negative attitude towards food safety significantly correlated to and successfully predicted trust in food safety regarding ways of shopping, food quality, and purchasing motives. Conclusion: Malaysian Chinese college students with positive or negative attitude towards food safety were able to predict different behaviors concerning their trust in food safety. Those with positive attitude towards food safety tended to enjoy various cooking methods and share food with friends and family members. Those with negative attitude towards food safety most likely would shop cautiously, choose most fresh and healthy food, read into product labels, and believe advertised food.
\end{abstract}

Keywords Trust, Attitude, Food Safety

\section{Introduction}

Food safety has become a global issue nowadays. World Health Organization reported that meat was associated with a high risk of cancer [1]. Toxic food incidents were reported in many countries, such as Malaysia, Taiwan, China, Hong Kong, Korea, and Japan. Several incidents were reported in Malaysia recently, such as toxic baby formula scandals in 2008 and 2013, polluted Shin Ramyun instant noodles in 2012, and Master Kong instant noodles in 2014 [2-6].

Food safety included handling, preparation, and storage of food properly to prevent foodborne illness. These incidents not only threatened individuals' health, but also influenced public's attitude and lowered their trust in food safety. A person's attitude and trust in food safety were highly correlated [7]. Trust in food safety was viewed as a subjective perception of food consumption that formed the foundation of consumer confidence in food safety [8]. However, attitude might be positive or negative. Trust in food safety had several dimensions, such as the ways of shopping, food quality, cooking methods, consumption situation, and purchasing motives [9]. The questions concerning the relations among different attitudes and dimensions of trust in food safety remain unsolved.

Public's negative attitude and low trust in food safety caused by food safety incidents may arouse public worry and panic $[10,11]$. It's important to understand people's psychological responses to food safety incidents. However, there were few studies investigated such topics in Malaysia. Therefore, the purpose of this study was to explore the relation among different attitudes towards food safety and dimensions of trust in food safety in Malaysia. We examined a) the correlations between positive attitude and the dimensions of trust in food safety, b) the correlations between negative attitude and the dimensions of trust in food safety, 3) the predictions of the dimensions of trust in food safety by positive attitude, and 4) the predictions of the dimensions of trust in food safety by negative attitude.

\section{Methods}

\section{Participants}

There were 108 Malaysian Chinese college students (42 men, 65 women, average age 21.85 ) voluntarily participated in online survey. Malaysian Chinese were overseas Chinese who lived in Malaysian. We recruited participants aged 18-and-up through snowball sampling.

\section{Trust in food safety}

Trust in food safety referred to an individual's expectation and belief toward food being safe and not harmful to people's health and environment [12]. Food Related Lifestyle Instrument was used to assess the trust in food safety [9]. Trust in food safety had five dimensions including ways of shopping, food quality, cooking methods, 
consumption situation, and purchasing motives. Ways of shopping referred to how consumers shopping for food and factors influencing their decision in food selection. Secondly, food quality was what kinds of food quality consumers concerned, such as freshness, health, taste and etc. Third, cooking methods referred to the procedure and time spent in meal preparation. Next, consumption situation was the habit of having meals with certain people or in certain circumstance. Lastly, purchasing motives referred to the expectation of food quality and brand preference. The scale ranged from 69 to 483 and comprised of 69 7-point Likert questions, with 1 indicating completely disagree and 7 indicating completely agree. Higher scores indicated higher trust in food safety.

\section{Attitude toward food safety}

Attitude towards food safety referred to an individual's opinion and behavior concerning the occurrence of food safety incidents and issues. Consumer Confidence in the Safety of Food Instruments was used to evaluate attitude toward food safety incidents under intensive exposure of media [13, 14]. Attitude towards food safety included positive and negative aspects; the scale ranged from 26 to 130 and consisted of 265 -point Likert questions with 1 indicating strongly disagree and 5 indicating strongly agree.

\section{Data analysis}

Pearson product-moment correlation coefficient analysis was used to investigate the correlations between attitude and trust in food safety. Linear regression analysis was used to examine the prediction of trust in food safety by attitude toward food safety.

\section{Results}

Table 1 shows the correlations between attitude and trust in food safety. Positive attitude was significantly and positively correlated with cooking methods and consumption situation. Negative attitude was significantly and positively correlated with ways of shopping, food quality, and purchasing motives. Table 2 presents the results of five regression models. Positive attitude significantly predicted trust in food safety in cooking methods and consumption situation. Negative attitude significantly predicted trust in food safety in ways of shopping, food quality, and purchasing motives.

Table 1. Correlation between attitude and trust in food safety $(N=108)$

\begin{tabular}{|c|c|c|}
\hline \multirow{2}{*}{ Variable } & \multicolumn{2}{|c|}{ Attitude } \\
\cline { 2 - 3 } & Positive & Negative \\
\hline Ways of shopping & 0.173 & $0.308^{* *}$ \\
\hline Food Quality & -0.087 & $0.304^{* *}$ \\
\hline Cooking methods & $0.196^{*}$ & 0.185 \\
\hline Consumption Situation & $0.222^{*}$ & 0.154 \\
\hline Purchasing Motives & -0.076 & $0.316^{* *}$ \\
\hline
\end{tabular}

$* p<0.05, * * p<0.01$
Table 2. Results of regression models

\begin{tabular}{|c|c|c|c|c|}
\hline Model & Predictors/Attitude & $F$ & $p$ & $\begin{array}{c}\text { Adjusted } \\
R^{2}\end{array}$ \\
\hline \multirow{2}{*}{$\begin{array}{c}\text { 1. Ways of } \\
\text { shopping }\end{array}$} & Positive & 3.256 & 0.074 & 0.021 \\
\cline { 2 - 5 } & Negative & $11.116^{* *}$ & 0.001 & 0.086 \\
\hline \multirow{2}{*}{$\begin{array}{c}\text { 2. Food } \\
\text { Quality }\end{array}$} & Positive & 0.813 & 0.369 & -0.002 \\
\cline { 2 - 5 } & Negative & $10.809 * *$ & 0.001 & 0.084 \\
\hline $\begin{array}{c}\text { 3.Cooking } \\
\text { methods }\end{array}$ & Positive & $4.219 *$ & 0.042 & 0.029 \\
\cline { 2 - 5 } & Negative & 3.770 & 0.055 & 0.025 \\
\hline $\begin{array}{c}\text { 4.Consumption } \\
\text { Situation }\end{array}$ & Positive & $5.472 *$ & 0.021 & 0.040 \\
\cline { 2 - 5 } & Negative & 2.579 & 0.111 & 0.015 \\
\hline \multirow{2}{*}{$\begin{array}{c}\text { 5.Purchasing } \\
\text { Motives }\end{array}$} & Positive & 0.614 & 0.435 & -0.004 \\
\cline { 2 - 5 } & Negative & $11.792 * *$ & 0.001 & 0.092 \\
\hline
\end{tabular}

$* p<0.05, * * p<0.01$

\section{Discussion}

Our findings showed that different attitudes towards food safety were associated with different dimensions of trust in food safety. These findings generally support the previous finding about the correlation between attitude and trust in food safety [7]. Our results further differentiated such correlations by positive and negative attitudes and dimensions of trust. Positive attitude towards food safety were correlated to the cooking methods and consumption situation of trust in food safety. Negative attitude towards food safety were correlated to ways of shopping, food quality, and purchasing motives of trust in food safety.

Positive attitude towards food safety was able to successfully predict the trust in food safety in cooking methods and consumption situation. Malaysian Chinese college students with positive attitude most likely would prefer to cook at home, a safer way to prepare food and lower risk of illness [15]. They probably had a strong tendency to be willing to spend time in planning meals, trying new recipes, enjoying sharing food with friends and family members.

On the other hand, negative attitude toward food safety was able to successfully predict the trust in food safety in ways of shopping, food quality, and purchasing motives. When shopping for food, Malaysian Chinese college students with negative attitude might check prices, read labels cautiously, plan before shopping, and select the most fresh and nutritious food. The occurrences of food safety indicated food risk management problems and reduced confidence of consumer [16]. They might avoid certain brains, believe in experts' advices, and love to shop in specialty stores.

Our findings indicated the need of enhancing public's trust and developing stronger positive attitude towards food safety. Governmental health institutes should further promote correct concepts of food safety to public and food industry. Consumers should advance their knowledge about food safety. Consumers' healthy preferences in food 
purchase might influence food industry to produce food without harming consumer health. Food industry should examine professional ethical principles in the process of producing food. Comprehensive food safety regulations and policies in food preparation and distribution should be established and implemented thoroughly in order to guard public health.

\section{Conclusions}

Malaysian Chinese college students with positive or negative attitude towards food safety were able to predict different behaviors concerning their trust in food safety. Those with positive attitude towards food safety tended to enjoy various cooking methods and shared food with friends and family members. Those with negative attitude towards food safety most likely would shop cautiously and care about the freshness and nutrition of food. We suggest that government should promote food safety concepts, meanwhile thoroughly implement food safety regulations to protect public health.

\section{Appendix}

Part 1: Trust-in-food-safety (7-point Likert Scale)

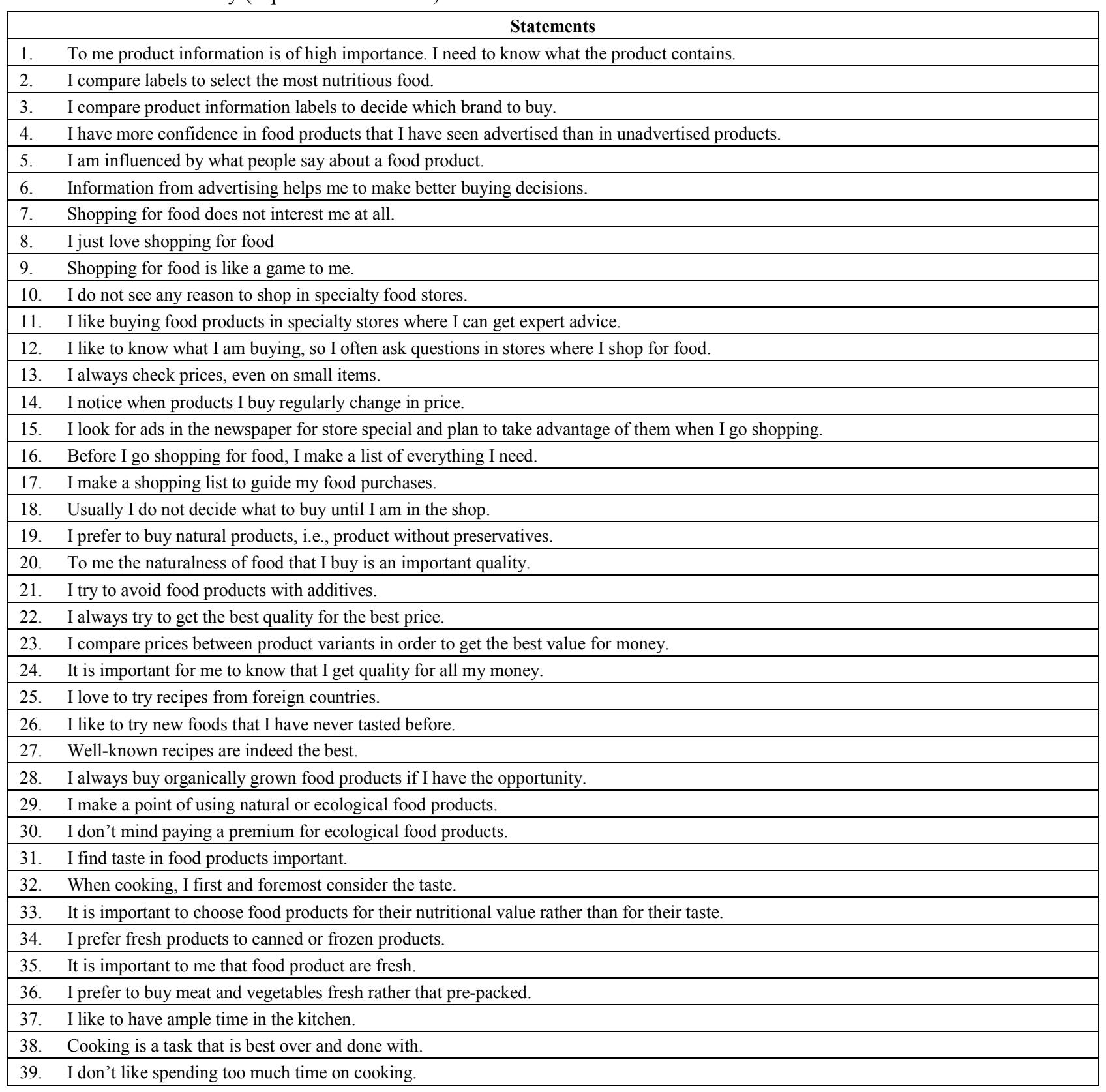




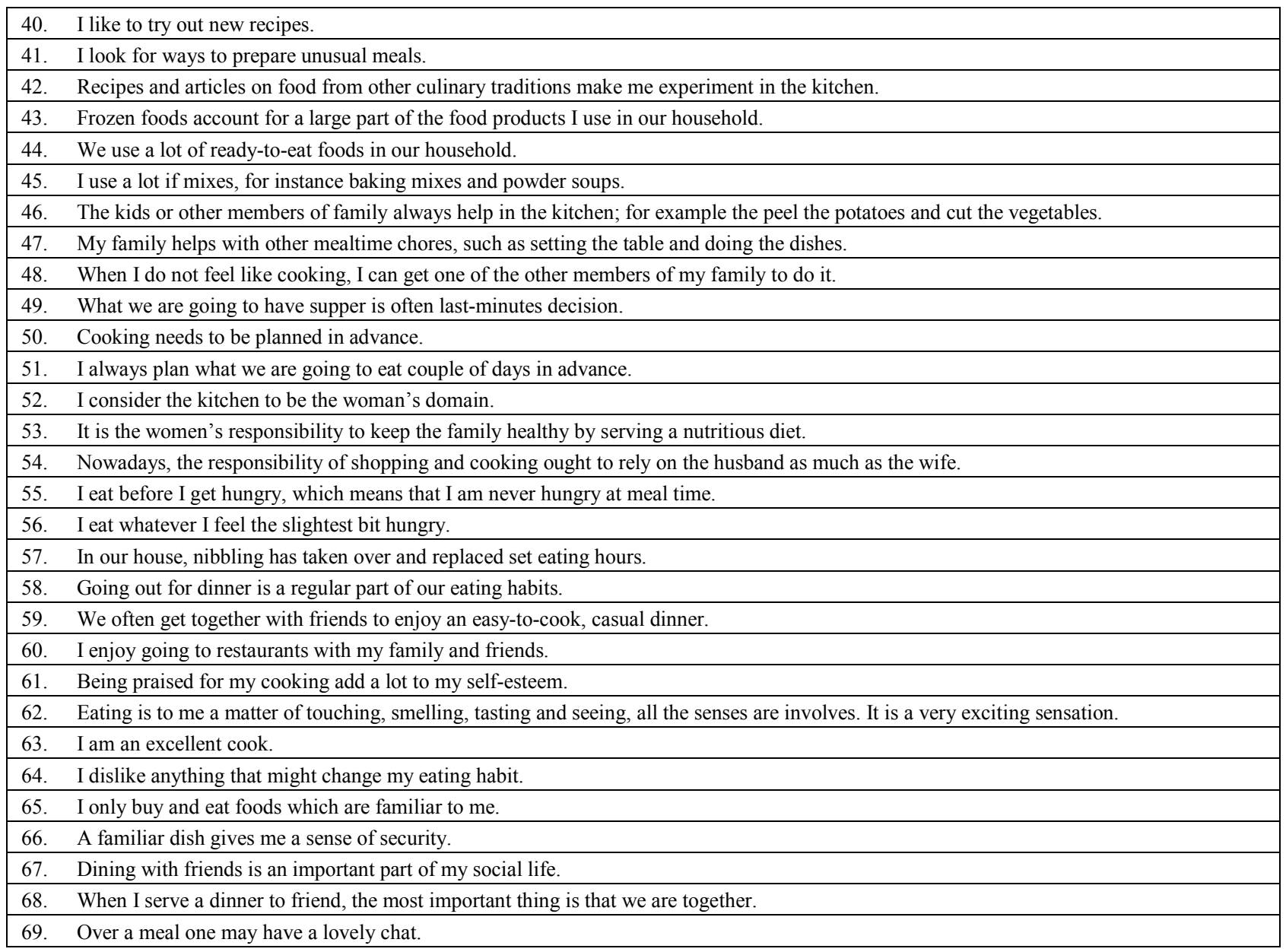

Part 2: Attitudes toward food safety (5-point Likert Scale)

\begin{tabular}{|c|}
\hline Statements \\
\hline Food products have never been as safe as nowadays. \\
\hline I believe food products are becoming increasingly safe. \\
\hline Food scares increase my concern about food safety. \\
\hline In recent months my confidence in food products has decreased. \\
\hline Generally there are few risks involved with food. \\
\hline Too often it happen that food products are sold in my place that are dangerous to consume. \\
\hline I worry about the safety of food. \\
\hline I do not have faith in the safety of food. \\
\hline I am afraid to become ill as a consequence of the products I eat. \\
\hline I am confident that food products are safe. \\
\hline I get very stressed when I think about food safety. \\
\hline I think the quality of food will increase. \\
\hline I feel uncomfortable regarding the safety of food. \\
\hline Generally food products are safe. \\
\hline Is a result of the occurrence of food safety incidents I am suspicious about certain food products. \\
\hline I feel frustrated about the problems that come up in the area of the safety of food. \\
\hline I believe few risks are involved in the consumption of food products. \\
\hline It scares me that there are problems with managing the safety of food. \\
\hline I am calm about all discussions about the safety of food. \\
\hline Problems that occur in the area of food safety make me angry. \\
\hline I feel hopeful about the developments in the area of food safety. \\
\hline I feel nervous when I think about the safety of food products. \\
\hline I am optimistic about the safety of food products. \\
\hline I panic as a result of food safety incidents that occur. \\
\hline I feel helpless as a consumer, with regard to the safety of food. \\
\hline I am satisfied with the safety of food products. \\
\hline
\end{tabular}




\section{REFERENCES}

[1] O'connor A. Meat is linked to higher cancer risk, W.H.O. report finds. New York Times. 2015, Oct. 26; Retrieved 2015, Oct. 27; from

http://www.nytimes.com/2015/10/27/health/report-links-som e-types-of-cancer-with-processed-or-red-meat.html?_r=1.

[2] Sin Chew Daily News. Malaysia Importers: Master soup ingredients including lard shelves destruction. Sin Chew Daily News. 2014, Sep. 16; Retrieved 2015, Sep. 26; from http://news.sinchew.com.my/node/386926?tid=1 (in Chinese).

[3] Sin Chew Daily News. Instant noodles suspected containing carcinogenesis. Sin Chew Daily News. 2012, Oct. 27; Retrieved 2015, Aug, 26; from http://news.sinchew.com.my/node/266185?tid=1 (in Chinese).

[4] Branigan T. Chinese figures show fivefold rise in babies sick from contaminated milk. The Guardian (London). 2008, Dec. 2; Retrieved 2015, Aug. 23; from http://www.guardian.co.uk/world/2008/dec/02/china..

[5] McDonald S. Nearly 53,000 Chinese children sick from milk. Associated Press. 2008, Sep. 22; Retrieved 2015, Aug. 23; from http://www.nbenews.com/id/26827110/.

[6] Macartney J. China baby milk scandal spreads as sick toll rises to 13,000.The Times (London). 2008, Sep. 22; Retrieved 2015, Aug. 23 from

http://www.timesonline.co.uk/tol/news/world/asia/article480 0458.ece.

[7] Toh PS, Birchenough A. Food safety knowledge and attitudes: culture and environment impact on hawkers in Malaysia.:

Knowledge and attitudes are key attributes of concern in hawker foodhandling practices and outbreaks of food poisoning and their prevention. Food Control. 2000;11(6):447-52.

[8] Röhr A, Lüddecke K, Drusch S, Müller MJ, Alvensleben Rv. Food quality and safety-consumer perception and public health concern. Food Control. 2005;16(8):649-55.

[9] Brunsø K, Grunert KG. Cross-Cultural Similarities and Differences in Shopping for Food. Journal of Business Research. 1998;42(2):145-50.

[10] Li J-H, Yu W-J, Lai Y-H, Ko Y-C. Major food safety episodes in Taiwan: Implications for the necessity of international collaboration on safety assessment and management. The Kaohsiung Journal of Medical Sciences. 2012;28(7, Supplement):S10-S6.

[11] Soon JM, Singh H, Baines R. Foodborne diseases in Malaysia: A review. Food Control. 2011;22(6):823-30.

[12] de Jonge J, Frewer L, Hans van T, Renes RJ, et al. Monitoring consumer confidence in food safety: an exploratory study. British Food Journal. 2004;106(10/11):837-49.

[13] de Jonge J, van Trijp H, Goddard E, Frewer L. Consumer confidence in the safety of food in Canada and the Netherlands: The validation of a generic framework. Food Quality and Preference. 2008;19(5):439-51.

[14] Haythornthwaite C. A social network study of the growth of community among distance learners. Information Research. 1998;4(1):4-1.

[15] Wilcock A, Pun M, Khanona J, Aung M. Consumer attitudes, knowledge and behaviour: a review of food safety issues. Trends in Food Science \& Technology. 2004;15(2):56-66.

[16] Chen M-F. Consumer's trust-in-food-safety typology in Taiwan: Food-related lifestyle matters. Health, Risk \& Society. 2011;13(6):503-26. 